\title{
Effect of $\beta$-glycosidase Supplementation on Vinasse Saccharification and L-lactic Acid Fermentation
}

\author{
Yingnan Cao, ${ }^{\mathrm{a}, \mathrm{d}}$ Juan Wang, ${ }^{\mathrm{b}}$ Qunhui Wang, ${ }^{\mathrm{c}}$ Jianguo Liu, ${ }^{\mathrm{d}}$ Tingxi Liu, ${ }^{\mathrm{a} *}$ \\ Charles W. Knapp, ${ }^{\mathrm{e}}$ and Yi Wang ${ }^{\mathrm{d}}$
}

\begin{abstract}
Efficient pretreatment and enzymatic hydrolysis is critical to achieve effective utilization of lignocellulosic biomass. In this study, the cellulase composition for lignocellulosic biomass hydrolysis was strategically optimized to improve the efficiency of vinasse saccharification and thus enhance L-lactic acid production. The results showed that the supplementation of $\beta$-glycosidase (BG) increased sugar production, and the glucose concentration exceeded cellobiose concentration after $48 \mathrm{~h}$ of hydrolysis. These results suggested that the addition of BG aided the hydrolysis of cellobiose and reduced the inhibitory effects caused by sugar accumulation. After $72 \mathrm{~h}$ to $96 \mathrm{~h}$ of hydrolysis, the BG supplementation improved cellobiose and glucose production by $25.7 \%$ and $27.4 \%$, respectively. The effect of BG supplementation on L-lactic acid production during the fermentation of microwave-alkali pretreated vinasse was also investigated. Here, the L-lactic acid production from simultaneous saccharification and fermentation (SSF) with the addition of BG was $20.8 \%$ higher than that without BG addition, and was also $37.0 \%$ higher than production from separate hydrolysis and fermentation with $B G$ addition. These results indicated the utilization efficiency of lignocellulosic biomass for L-lactic acid production could be enhanced by supplementation of BG in SSF.
\end{abstract}

Keywords: Coupled microwave-alkali pretreatment; $\beta$-glycosidase; Product inhibition; Cellobiose; L-lactic acid; Vinasse.

Contact information: a: Water Conservancy and Civil Engineering College, Inner Mongolia Agricultural University, 306 Zhaowuda Road, Saihan District, Huhhot 010018, China; b: School of Civil Engineering, Inner Mongolia University of Technology, 49 Aimin Road, Xincheng District, Huhhot 010051, China; c: Department of Environmental Engineering, University of Science and Technology Beijing, 30 Xueyuan Road, Haidian District, Beijing 100083, China; d: College of Energy and Power Engineering, Inner Mongolia University of Technology, 49 Aimin Road, Xincheng District, Huhhot 010051, China;

e: Department of Civil \& Environmental Engineering, University of Strathclyde, 75 Montrose Street, Glasgow, G1 1XJ, United Kingdom; *Corresponding author: txliu1966@163.com

\section{INTRODUCTION}

Lignocellulosic materials represent the most abundant type of biomass on earth, and their efficient utilization has attracted widespread attention globally (Kumar et al. 2017). Vinasse is a by-product of wine production, and approximately 6 million tons to 8 million tons of solid vinasse is produced in China every year (Shi 2006). Wine vinasse has a high content of lignocellulose, with cellulose/hemicellulose content greater than $48 \%$ by mass (Liu et al. 2013). Most vinasse is stored or disposed untreated, which occupies land and causes serious environmental problems due to its high biological oxygen demand and acidic nature.

A common treatment of the lignocellulosic material involves pretreatment, enzymatic hydrolysis, and then fermentation of hydrolysate to produce high value-added 
products, including ethanol, L-lactic acid, hydrogen, and biogas (Antonopoulou et al. 2016; Du et al. 2016; Wang et al. 2017). L-lactic acid is a raw material that is used for the production of polylactic acid, a biodegradable plastic that has wide application prospects and great market demand. Therefore, production of L-lactic acid with high optical purity from lignocellulosic materials has attracted broad interest (Abdel-Rahman et al. 2011; Jin et al. 2015). However, the complex fiber structure and low enzymatic hydrolysis efficiency of lignocellulosic materials limits their commercial utilization (Berlin et al. 2006).

There have been numerous studies on the pretreatment and enzymolysis of cellulosic biomass (Taherzadeh and Karimi 2008; Hendriks and Zeeman 2009; Tomáspejó et al. 2010). The main enzymes used to hydrolyse cellulose in lignocellulosic materials include endoglucanase (EG), cellobiohydrolase (CBH), and $\beta$-glucosidase (BG) (Jalak et al. 2012; Kostylev and Wilson 2012). During cellulose hydrolysis, EG randomly attacks $\beta$-1,4-glycosidic bonds within the polymer chains to generate cello-oligosaccharides of varying lengths. Cello-oligosaccharides are then cleaved by $\mathrm{CBH}$ either from reducing ends (by $\mathrm{CBH}$ I) or from non-reducing ends (by $\mathrm{CBH}$ II), thus resulting in the generation of cellobiose. Finally, BG is used to hydrolyse cellobiose into glucose. Unbalanced cellulase enzyme composition may lead to low enzymatic hydrolysis efficiency and product inhibition, which can adversely affect glucose production and further L-lactic acid production. Cellobiose, the intermediate product of hydrolysis, and glucose, the endproduct, have strong inhibiting effects on $\mathrm{CBH}$ and $\mathrm{BG}$, respectively (Holtzapple et al. 1990; Gruno et al. 2004). Supplementation of BG can effectively reduce the inhibition effect of cellobiose on CBH and BG (Subramaniyan and Prema 2002; Andriä et al. 2010;). Shi et al. (2013) optimized cellulase composition by co-fermentation of Trichoderma reesei and Aspergillus niger to obtain higher sugar production. However, the role of cellulase optimization on promoting the cellulose hydrolysis and subsequent L-lactic acid fermentation has not yet been reported.

In a previous study microwave-assisted alkali pretreatment was found to be the most suitable pretreatment strategy for vinasse. The optimal pretreatment conditions were microwave power $523 \mathrm{~W}$, a pretreatment time of $8 \mathrm{~min}$, and $\mathrm{NaOH}$ dosage $0.06 \mathrm{~g} / \mathrm{g}$ vinasse (Liu et al. 2012; 2013). Based on this result, cellulase composition was analysed and optimized to build a cellulase preparation with increased enzyme activity, the synergistic effect between the enzyme components was determined, and the effect and mechanism of enzyme composition optimization on L-lactic acid production was investigated.

\section{EXPERIMENTAL}

\section{Materials}

Vinasse was obtained from a distillery in Beijing, which used sorghum for brewing and rice husk as an auxiliary material to adjust porosity. The characteristics of the vinasse are shown in Table 1. Cellulose and hemicellulose represented $48.4 \%$ of the dry matter (DM). The vinasse contained only a small amount of crude protein and crude fat $(<5 \%$ DM each).

Industrial cellulase (270 U/g) was purchased from Beijing Donghua Qiangsheng Biotechnology Co., Ltd. (Beijing, China) and $\beta$-glycosidase (BG) was purchased from Sigma G4511 (CAS\# 9001-22-3; 20 U/mg to 40 U/mg activity; St. Louis, MO, USA). The fermentative bacteria Lactobacillus casei (CICC 6106) was acquired from China Centre of Industrial Culture Collection. Chromatography-grade reagents were used for liquid 
chromatography analysis, and analytical grade reagents were used for other analysis.

Table 1. Characteristics of the Vinasse

\begin{tabular}{|c|c|c|c|}
\hline Parameters & Content $^{*}(\%)$ & Parameters & Content $^{*}(\%)$ \\
\hline Soluble reducing sugar & $1.00 \pm 0.30$ & Cellulose & $27.23 \pm 0.04$ \\
\hline Soluble total sugar & $2.12 \pm 0.34$ & Hemicellulose & $21.17 \pm 0.69$ \\
\hline L-lactic acid & $3.26 \pm 0.80$ & Lignin & $14.95 \pm 0.52$ \\
\hline Crude protein & $0.78 \pm 0.02$ & Water & $66.67 \pm 0.40$ \\
\hline Crude fat & $4.90 \pm 0.10$ & $\mathrm{pH}$ & 3.45 \\
\hline
\end{tabular}

${ }^{*}$ Components of the vinasse (except water content) were based on dry matter

\section{Pretreatment of Vinasse and Enzymatic Hydrolysis}

The microwave-assisted alkali pretreatment was performed in $500 \mathrm{~mL}$ Erlenmeyer flasks containing $20 \mathrm{~g}$ of vinasse (DM) and $160 \mathrm{~mL}$ of water. The $\mathrm{NaOH}$ dosage was 0.06 $\mathrm{g} / \mathrm{g}$ vinasse $(\mathrm{DM})$. The flask was placed into a microwave and heated at $523 \mathrm{~W}$ for $8 \mathrm{~min}$. The flask was then allowed to cool at room temperature for $2 \mathrm{~h}$, and water was added to the samples to supplement the evaporative losses (Liu et al. 2012). After pretreatment, the cellulose, hemicellulose, and lignin content of the vinasse was $36.2 \%, 17.2 \%$, and $12.8 \%$, respectively.

Enzymatic hydrolysis of the pretreated vinasse was performed in $200 \mathrm{~mL}$ Erlenmeyer flasks containing $5 \mathrm{~g}$ of vinasse (DM) and $75 \mathrm{~mL}$ of $50 \mathrm{mM}$ sodium citrate buffer ( $\mathrm{pH}$ 6.0) with a specific dosage of cellulase at $40{ }^{\circ} \mathrm{C}$ for $96 \mathrm{~h}$. The hydrolysis reactions were terminated by heating the mixtures at $95{ }^{\circ} \mathrm{C}$ for $5 \mathrm{~min}$. The hydrolysis efficiency was calculated with Eq. 1,

$$
\text { Hydrolysis efficiency }(\%)=\frac{\left(C_{\text {Cellobiose }} \times \frac{360}{342}+C_{\text {Glucose }}\right) \times V_{\text {Hydrolysat }} \times 0.9}{W_{\text {Vinasse }} \times \eta_{\text {Glucan }}} \times 100
$$

where $C_{\text {Cellobiose }}$ and $C_{\text {Glucose }}$ denote the cellobiose and glucose concentration after hydrolysis, respectively, $V_{\text {Hydrolysate }}$ denotes the volume of the hydrolysate, and $W_{\text {Vinasse }}$ and $\eta_{\text {Glucan }}$ denote the weight and glucan content of the vinasse used for enzymatic hydrdysis, respectively.

\section{Separate Hydrolysis and Fermentation (SHF) and Simultaneous Saccharification and Fermentation (SSF)}

To carry out SHF, pretreated vinasse was placed in Erlenmeyer flasks for enzymatic hydrolysis. The cellulase dosage was $60.6 \mathrm{U} / \mathrm{g}$ vinasse (DM). After hydrolysis for $72 \mathrm{~h}$, the mixture was centrifuged at $4000 \times g$ for $10 \mathrm{~min}$, and $150 \mathrm{~mL}$ of supernatant was placed in a $250 \mathrm{~mL}$ fermentation bottle for fermentation. Exactly $10 \mathrm{~mL}$ of inoculum was centrifuged at $4000 \times g$ for $15 \mathrm{~min}$, and the settled cells were inoculated to the fermentation medium. The fermentation was performed at $35^{\circ} \mathrm{C}$ and $50 \mathrm{rpm}$ under anaerobic conditions.

The SSF was performed in a $250 \mathrm{~mL}$ fermentation bottle that contained $10 \mathrm{~g}$ of pretreated vinasse (DM) and $150 \mathrm{~mL}$ of $50 \mathrm{mM}$ sodium citrate buffer $(\mathrm{pH} \mathrm{6.0)}$. The cellulase dosage was $60.6 \mathrm{U} / \mathrm{g}$ vinasse (DM). Exactly $10 \mathrm{~mL}$ of inoculum was centrifuged at $4000 \times g$ for $15 \mathrm{~min}$, and the settled cells were inoculated to the fermentation medium. SSF was performed at $35{ }^{\circ} \mathrm{C}$ and $50 \mathrm{rpm}$ under anaerobic conditions. The L-lactic acid yield $(\mathrm{g} / \mathrm{g}$ ) was defined as amount of L-lactic acid $(\mathrm{g})$ divided by total reducing sugar $(\mathrm{g})$. 


\section{Analytical Methods}

The activities of the industrial cellulase (carboxymethyl cellulase activity (CMCase), filter paper activity (FPA) and BG activity) were measured according to the standard (IUPAC 1987). The sugar concentration of the hydrolysate was determined by a high-performance liquid chromatography (HPLC) system (LC-20AT, Shimadzu, Tokyo, Japan) equipped with an Inertsil $\mathrm{NH}_{2}$ Column $(4.6 \mathrm{~mm} \times 250 \mathrm{~mm}, 5 \mu \mathrm{m})$ and a refractive index detector (RID-10A, Shimadzu) at $40{ }^{\circ} \mathrm{C}$, using $25 \%$ water- $75 \%$ acetonitrile at a flow rate of $1.0 \mathrm{~mL} / \mathrm{min}$ as the mobile phase. The injection volume was $5 \mu \mathrm{L}$.

L-lactic acid was detected by HPLC (LC-20AT, Shimadzu) using a Chiral column (CHIRALPAK MAt, $4.6 \mathrm{~mm} \times 50 \mathrm{~mm}, 5 \mu \mathrm{m}$ ) and an ultraviolet absorption detector at 254 $\mathrm{nm}$. A $2 \mathrm{mmol} / \mathrm{L}$ copper sulphate solution at a flow rate of $1.0 \mathrm{~mL} / \mathrm{min}$ was used as the mobile phase. The injection volume was $5 \mu \mathrm{L}$.

\section{RESULTS AND DISCUSSION}

\section{Component Characteristics of the Industrial Cellulase}

The degradation of crystalline cellulose was not possible with a single enzyme but required the synergistic actions of at least three groups of enzymes: $\mathrm{EG}, \mathrm{CBH}$, and $\mathrm{BG}$ (Tsai et al. 2014). Among them, EG and CBH catalyze the hydrolysis of cellulose-topolysaccharide and polysaccharide-to-cellobiose, respectively, and BG is the key enzyme that catalyzes the hydrolysis of cellobiose to glucose (Zhang and Lynd 2004). The three enzymes synergistically hydrolyze the cellulose to glucose. Commercial cellulase usually contains all three groups of enzymes. The comprehensive hydrolysis ability of the three enzymes can be represented by FPA. Filter paper is a fibrous material with medium polymerization degree and crystallinity. When measuring the FPA of the cellulose, filter paper is used as the substrate for enzymatic hydrolysis and the amount of reducing sugar produced after hydrolysis can represent the saccharifying ability of the cellulase. This method has been widely used, and can reflect the synergy of three kinds of enzyme components. However, the BG activity in industrial cellulase is usually low, resulting in cellobiose accumulation and consequently reducing the hydrolysis efficiency; thus, an increased cellulase dosage and higher production costs are required (Gusakov and Sinitsyn 1992; Bozeman and Murdock 1995; Kruus et al. 1995; Medve et al. 1998).

The industrial cellulase used in this study was food-grade and had the highest activity among commercial cellulases. The activities of the three groups of enzyme and FPA were shown in Fig. 1. Among the three enzymes, the activities of EG and CBH reached $34300 \mathrm{U} / \mathrm{g}$ and $15900 \mathrm{U} / \mathrm{g}$, respectively, while BG had a much lower activity (5540 $\mathrm{U} / \mathrm{g}$ ). The average activity of the three enzymes was $18700 \mathrm{U} / \mathrm{g}$, which was 5.4 times greater than FPA $(3450 \mathrm{U} / \mathrm{g})$. This result suggested that although the individual activities of the three enzymes were relatively high, the overall hydrolysis ability (i.e., FPA) was well below the lowest of activity of the three components (i.e., BG, $5540 \mathrm{U} / \mathrm{g}$ ). This was likely due to the cellobiose inhibition (product inhibition) caused by the unbalanced enzyme activity.

The comprehensive hydrolysis ability relies not only on enzyme dosage, but also on the proportion of the enzyme components (Schwarz 2001). Zhu et al. (2006) showed that adding BG to the commercial cellulase caused enhancement in both the initial rates and degree of solubilization of cellulose. Therefore, the current study investigated the hydrolysis efficiency of cellulase after supplementing three individual enzymes at a dosage 
of 2000 U/g. As shown in Fig. 1, supplementation of EG and CBH did not improve FPA, while the addition of BG increased FPA by $51.6 \%$. This indicated that the FPA was limited by the BG activity. As the FPA represents the hydrolysis ability of the cellulose to glucose, the BG activity was the factor that restricted enhancement of enzymatic hydrolysis efficiency. Similar results have been observed in other studies (Lamed et al. 1991; Kim et al. 2015).

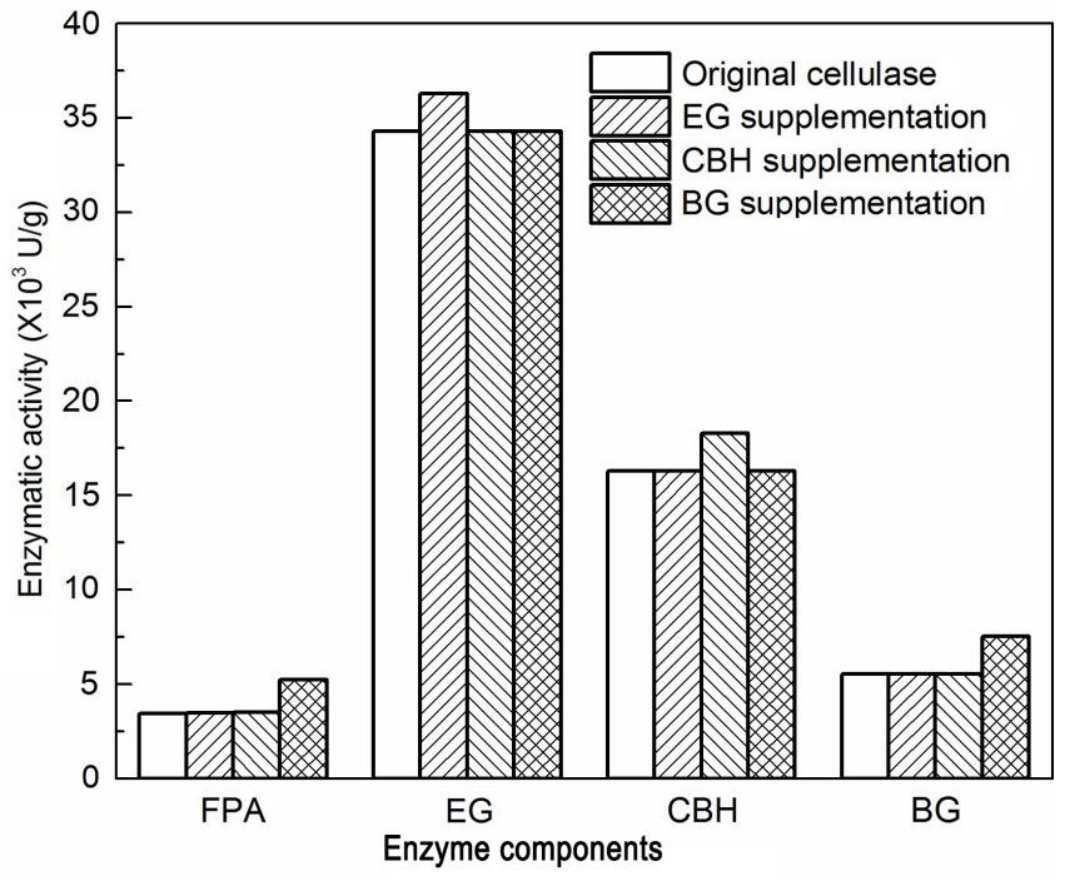

Fig. 1. Enzyme activities of cellulase before and after supplementation of $2000 \mathrm{U} / \mathrm{g}$ with three different components of the cellulase

\section{Effect of BG Supplementation on FPA}

To improve the activity of the cellulase, BG was incrementally supplemented to optimise cellulase performance. As shown in Fig. 2, the FPA of the enzyme mixture increased with increased dosages of BG. However, at BG supplementation levels less than $4000 \mathrm{U} / \mathrm{g}$, the FPA of the enzyme mixture remained less than the total BG activity (existing combined with supplemented). The maximum FPA activity (12400 U/g) was achieved when BG supplementation was $5000 \mathrm{U} / \mathrm{g}$. No further FPA improvement occurred at BG supplementations of less than $5000 \mathrm{U} / \mathrm{g}$. The correlation analysis indicated that the total BG activity directly related with FPA performance $\left(r^{2}=0.97\right)$.

\section{Enhanced Vinasse Hydrolysis by BG Supplementation}

The effect of BG supplementation on the enzymatic hydrolysis of the alkalimicrowave-pretreated vinasse was studied. The FPA of the enzyme mixture with and without BG supplementation was $12400 \mathrm{U} / \mathrm{g}$ and $3950 \mathrm{U} / \mathrm{g}$, respectively. As shown in Fig. 3 , during the hydrolysis with BG addition, the glucose and cellobiose concentration reached $11.04 \mathrm{~g} / \mathrm{L}$ and $9.33 \mathrm{~g} / \mathrm{L}$, respectively, which was $27.4 \%$ and $25.7 \%$ higher than that without BG addition, respectively. During hydrolysis of the mixture with added BG, the concentration exceeded the cellobiose concentration $12 \mathrm{~h}$ sooner than the mixture without $\mathrm{BG}$ addition, suggesting that adding $\mathrm{BG}$ enhanced the conversion of cellobiose to glucose. 


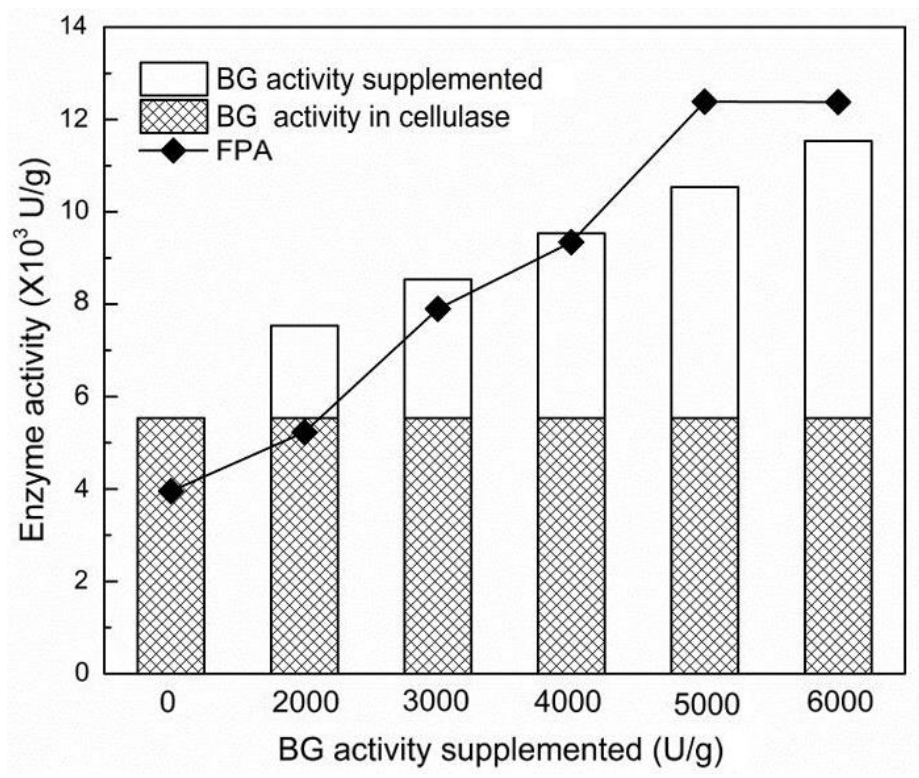

Fig. 2. Effect of BG supplementation on FPA of the enzyme mixture

As shown in Fig. 3b, the cellobiose and glucose concentration continued to increase at the end of the hydrolysis ( $72 \mathrm{~h}$ to $96 \mathrm{~h}$ ). This indicated that the addition of BG had improved the hydrolysis of cellobiose to glucose, which relieved the product inhibition caused by cellobiose and promoted the overall hydrolysis efficiency of the enzyme mixture.

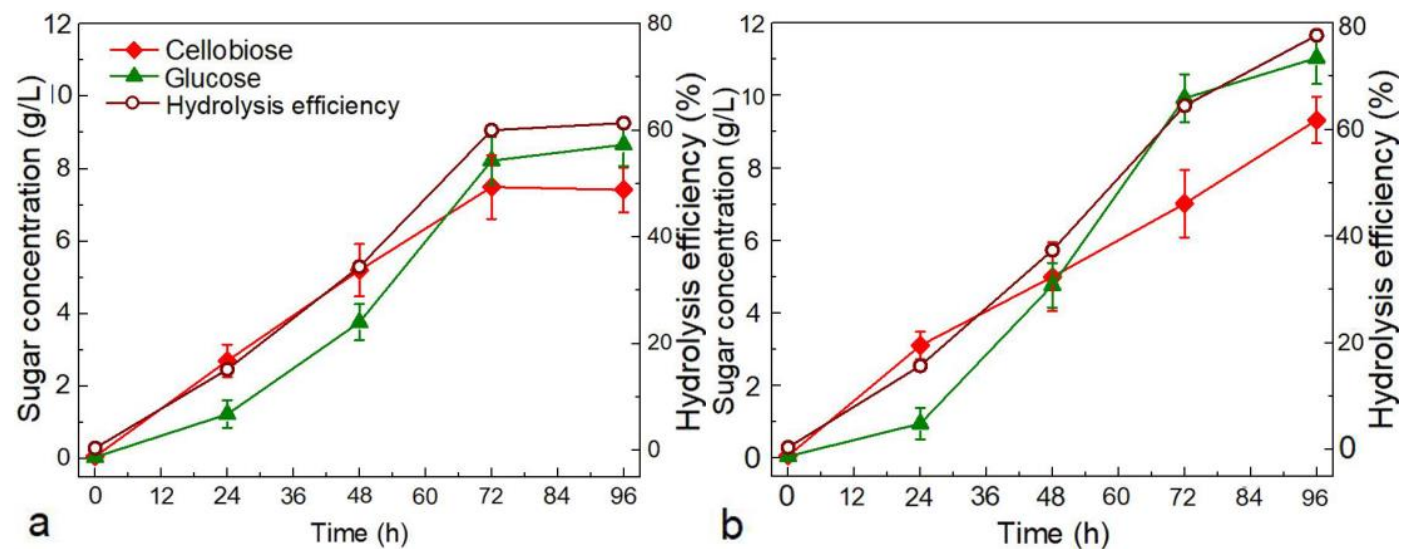

Fig. 3. Changes of sugar concentration and hydrolysis efficiency during the hydrolysis of microwave-alkali pretreated vinasse without (a) and with (b) BG supplementation

After $96 \mathrm{~h}$ of hydrolysis, the hydrolysis efficiency of vinasse with BG supplementation was $77.7 \%$, which was $26.6 \%$ higher than the efficiency of vinasse without BG supplementation. This result suggested that, besides increasing the cellulase dosage, optimizing the proportion of the cellulase components can also obtain a high FPA, thus improving the overall hydrolysis efficiency. Chen et al. (2007) supplemented the cellulase solution from Trichoderma reesei with BG obtained from Aspergillus niger, and the hydrolysis efficiency reached $83.9 \%$ with a dosage of $6.5 \mathrm{IU} / \mathrm{g}$ substrate. Long et al. (2012) found that the hydrolysis efficiency increased by $13.82 \%$ with the addition of BG (6 IU/g.). These results were consistent with the current study. 


\section{Effect of BG Supplementation on L-lactic Acid Production}

SHF and SSF are the two most common fermentation methods for L-lactic acid production. Figure 4 shows the changes of L-lactic acid, cellobiose, and glucose concentrations during the fermentation of microwave-alkali pretreated vinasse.

For SHF with BG addition (Fig. 4b), the initial cellobiose and glucose concentrations were $9.33 \mathrm{~g} / \mathrm{L}$ and $11.04 \mathrm{~g} / \mathrm{L}$, respectively, which were higher than the concentrations obtained for vinasse without BG addition $(7.42 \mathrm{~g} / \mathrm{L}$ and $8.66 \mathrm{~g} / \mathrm{L}$, respectively, Fig. 4a). However, the maximum L-lactic acid concentration was $17.45 \mathrm{~g} / \mathrm{L}$, which was only $2.81 \mathrm{~g} / \mathrm{L}$ higher than the concentration of vinasse without BG addition, and the cellobiose was not completely consumed after $96 \mathrm{~h}$ of fermentation. This indicated that the addition of BG in SHF increased the glucose and cellobiose concentration during the hydrolysis process but did not significantly improve the conversion of sugar to L-lactic acid.
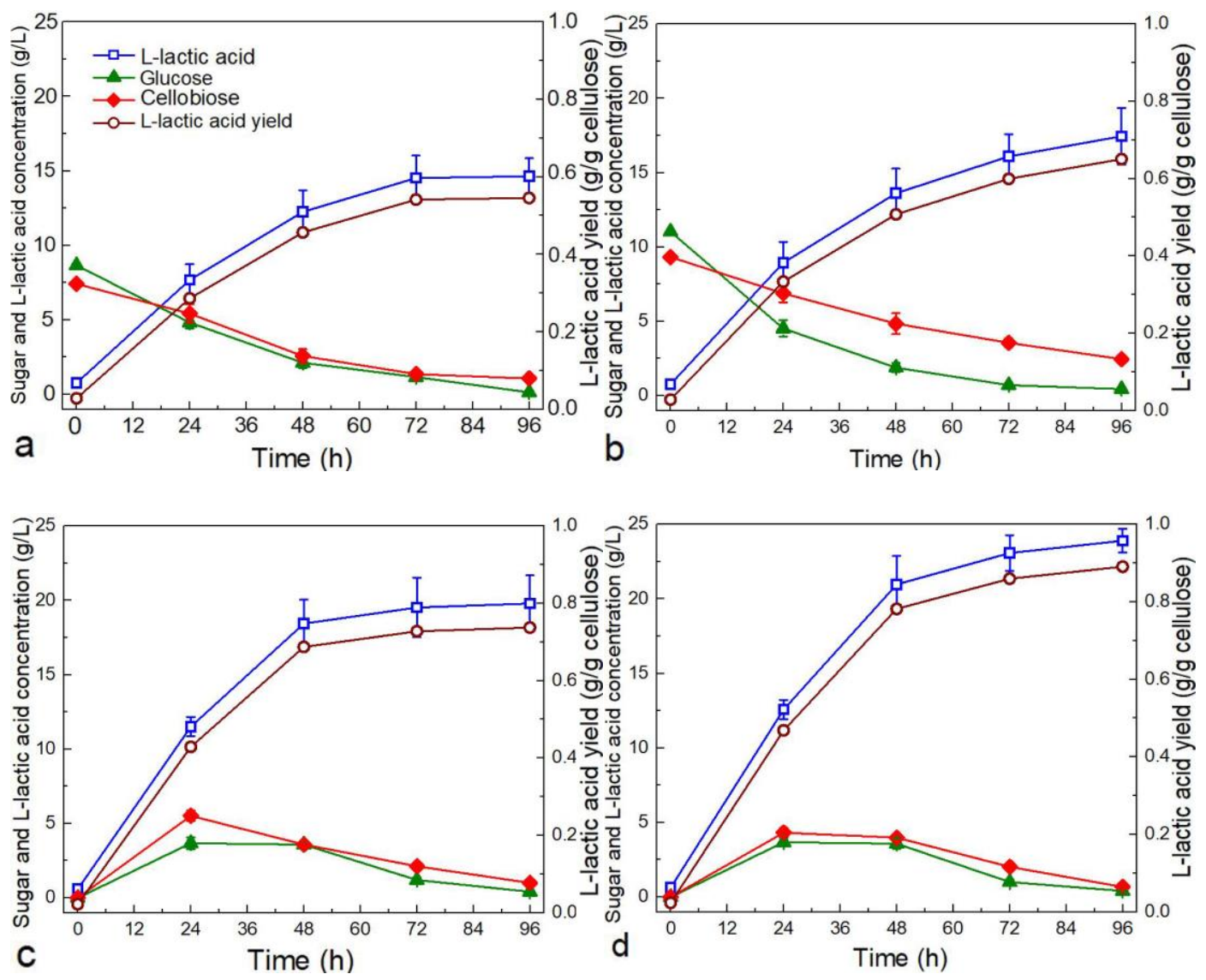

Fig. 4. L-lactic acid production by SHF and SSF: (a) SHF without BG supplementation, (b) SHF with BG supplementation, (c) SSF without BG supplementation, (d) SSF with BG supplementation

During the SSF process, the maximum cellobiose and glucose concentrations were observed at $24 \mathrm{~h}$, but the concentration never exceeded $6.0 \mathrm{~g} / \mathrm{L}$. Thus, inhibition caused by sugar accumulation was avoided. The L-lactic acid concentration of SSF with BG addition reached $23.90 \mathrm{~g} / \mathrm{L}$ (Fig. 4d), which was $20.8 \%, 37.0 \%$, and $63.2 \%$ greater than the concentrations of SSF without BG addition, SHF with BG addition, and SHF without BG addition, respectively. Moreover, the glucose and cellobiose were completely consumed. This result suggested that addition of BG in SSF not only improved the cellulose hydrolysis 
efficiency, but also promoted the overall utilization efficiency of the substrate.

Moreover, the L-lactic acid concentration in SSF with BG addition $(23.90 \mathrm{~g} / \mathrm{L})$ was higher than the total concentration of cellobiose and glucose during hydrolysis $(20.36 \mathrm{~g} / \mathrm{L})$. Though the hydrolysis was not performed at its optimal conditions during SSF, more cellulose was hydrolyzed in SSF than in SHF. This was likely because the inhibition of glucose and cellobiose on cellulose hydrolysis was relieved (Berlin et al. 2006; Zheng et al. 2013). Compared to SHF, the SSF with BG addition showed a distinct advantage in (1) high substrate hydrolysis efficiency and product yield; (2) shortened process time to complete the hydrolysis and fermentation.

\section{CONCLUSIONS}

1. The supplementation of BG significantly improved the hydrolysis efficiency of the microwave-assisted alkali pretreated vinasse.

2. The SSF fermentation mode avoided the inhibition effect caused by sugar accumulation, which improved the continuity of the hydrolysis and fermentation process and improved the L-lactic acid production.

3. Further research is needed to study the synergistic reaction mechanisms of the cellulase components to lay a good foundation for the industrialized application of lignocellulosic materials.

\section{ACKNOWLEDGMENTS}

This research was supported by the National Natural Science Foundation (No. 21666028); and the Inner Mongolia Autonomous Region Science and Technology Major Projects.

\section{REFERENCES CITED}

Abdel-Rahman, M. A., Tashiro, Y., and Sonomoto, K. (2011). "Latic acid production from lignocellulose-derived sugars using lactic acid bacteria: Oveview and limits," Journal of Biotechnology 156(4), 286-301. DOI: 10.1016/j.jbiotec.2011.06.017

Andriä, P., Meyer, A. S., Jensen, P. A., and Dam-Johansen, K. (2010). "Reactor design for minimizing product inhibition during enzymatic lignocellulose hydrolysis: I. Significance and mechanism of cellobiose and glucose inhibition on cellulolytic enzymes," Biotechnology Advances 28(3), 308-324. DOI:

10.1016/j.biotechadv.2010.01.003 
Antonopoulou, G., Vayenas, D., and Lyberatos, G. (2016). "Ethanol and hydrogen production from sunflower straw: The effect of pretreatment on the whole slurry fermentation," Biochmical Engineering Journal 116, 65-74. DOI: 10.1016/j.bej.2016.06.014

Berlin, A., Balakshin, M., Gilkes, N., Kadla, J., Maximenko, V., Kubo, S., and Saddler, J. (2006). "Inhibition of cellulase, xylanase and beta-glucosidase activities by softwood lignin preparations," Journal of Biotechnology 125(2), 198-209. DOI: 10.1016/j.jbiotec.2006.02.021

Chen, M., Xia, L. M., and Xue, P. J. (2007). "Enzymatic hydrolysis of corncob and ethanol production from cellulosic hydrolysate," International Biodeterioration and Biodegradation 59(2), 85-89. DOI: 10.1016/j.ibiod.2006.07.011

Du, J., Chen, G. Y., Huang, H. Y., Jin, H. M., Xi, Y. L., Qian, Y. T., Xu, Y. D., and Chang, Z. Z. (2016). "Effect of mild hydrothermal pretreatment on characteristics of anaerobic digestion and physico-chemical properties of rice straw," China Environmental Science.

Gruno, M., Väljamäe, P., Pettersson, G., and Johansson, G. (2004). "Inhibition of the Trichoderma reesei cellulases by cellobiose is strongly dependent on the nature of the substrate," Biotechnology and Bioengineering 86(5), 503-511. DOI: 10.1002/bit.10838

Gusakov, A. V., and Sinitsyn, A. P. (1992). "A theoretical analysis of cellulase product inhibition: effect of cellulase binding constant, enzyme/substrate ratio, and betaglucosidase activity on the inhibition pattern," Biotechnology and Bioengineering 40(6), 663-71. DOI: 10.1002/bit.260400604

Hendriks, A. T., and Zeeman, G. (2009). "Pretreatments to enhance the digestibility of lignocellulosic biomass," Bioresource Technology 100(1),10-18. DOI: 10.1016/j.biortech.2008.05.027

Holtzapple, M., Cognata, M., Shu, Y., and Hendrickson, C. (1990). "Inhibition of Trichoderma reesei cellulase by sugars and solvents," Biotechnology and Bioengineering 36(3), 275-87. DOI: 10.1002/bit.260360310

International Union of Pure and Applied Chemistry (IUPAC) (1987). Measurement of Cellulase Activities, New Delhi, India.

Jalak, J., Kurašin, M., Teugjas, H., and Väljamäe, P. (2012). "Endo-exo synergism in cellulose hydrolysis revisited," Journal of Biological Chemistry 287(34), 2880228815. DOI: $10.1074 /$ jbc.M112.381624

Jin, Z., Tashiro, Y., Wang, Q., and Sonomoto, K. (2015). "Recent advances to improve fermentative butanol production: Genetic engineering and fermentation technology," Journal of Bioscience and Bioengineering 119(1), 1-9. DOI: 10.1016/j.biosc.2014.05.023

Kim, I. J., Jung, J. Y., Lee, H. J., Park, H. S., Jung, Y. H., Park, K., and Kim, K. H. (2015). "Customized optimization of cellulase mixtures for differently pretreated rice straw," Bioprocess and Biosystems Engineering 38(5), 929-937. DOI: 10.1007/s00449-014-1338-7.

Kostylev, M., and Wilson, D. (2012). "Synergistic interactions in cellulose hydrolysis," Biofuels 3(1), 61-70. DOI: 10.4155/bfs.11.150 
Kruus, K., Lua, A. C., Demain, A. L., and Wu, J. H. (1995). "The anchorage function of CipA (CelL), a scaffolding protein of the Clostridium thermocellum cellulosome," PNAS USA 92(20), 9254-9258. DOI: 10.1073/pnas.92.20.9254

Kumar, A. K., and Sharma, S. (2017). "Recent updates on different methods of pretreatment of lignocellulosic feedstocks: a review," Bioresources and Bioprocessing 4(1),7-25 DOI: 10.1186/s40643-017-0137-9

Lamed, R., Kenig, R., Morgenstern, E., Calzada, J. F., Micheo, F. D., and Bayer, E. A. (1991). "Efficient cellulose solubilization by a combined cellulosome- $\beta$-glucosidase system," Applied Biochemistry and Biotechnology 27(2), 173-183. DOI: 10.1007/BF02921525

Liu, J., Wang, Q., Wang, S., Sun, X., Ma, H., and Tushiro, Y. (2013). "Effects of pretreatment on the microbial community and 1-lactic acid production in vinasse fermentation," Journal of Biotechnology 164(2), 260-265. DOI: 10.1016/j.jbiotec.2012.08.014

Liu, J., Wang, Q., Wang, S., Zou, D., and Sonomoto, K. (2012). "Utilisation of microwave-NaOH pretreatment technology to improve performance and 1-lactic acid yield from vinasse," Biosystems Engineering 112(1), 6-13. DOI: 10.1016/j.biosystemseng.2012.01.004

Long, C., Cheng, Y.,Wu, X., Liu, J., and Long, M. (2012). "Cloning and sequence analysis of cellulase genes from Hypocrea orientalis EU7-22," Biotechnology Bulletin 11, 110-117.

Schwarz, W. (2001). "The cellulosome and cellulose degradation by anaerobic bacteria," Applied Microbiology and Biotechnology 56(5-6), 634-639. DOI: $10.1007 / \mathrm{s} 002530100710$

Shi, A. H. (2006). "Present and future of environmentally friendly distillers' grains in China," China Brewing 3, 4-7.

Shi, T., Song, X., Ouyang, J., and Yong, Q. (2013). "Production of -glycosidase by coculturing NL02 and RUT-C30 in fermentation," Chemistry and Industry of Forest Products 33, 101-105.

Subramaniyan, S., and Prema, P. (2002). "Biotechnology of microbial xylanases: enzymology, molecular biology, and application," Critical Reviews in Biotechnology 22(1), 33-64. DOI: 10.1080/07388550290789450

Taherzadeh, M. J., and Karimi, K. (2008). "Pretreatment of lignocellulosic wastes to improve ethanol and biogas production: a review," International Journal of Molecular Sciences 9(9),1621-1651. DOI: 10.3390/ijms9091621

Tsai, C.T., Morales-Rodriguez, R., Sin, G., and Meyer, A.S. (2014). "A dynamic model for cellulosic biomass hydrolysis: a comprehensive analysis and validation of hydrolysis and product inhibition mechanisms," Applied Biochemistry and Biotechnology 172(6), 2815-2837. DOI: 10.1007/s12010-013-0717-x

Wang, J., Gao, M., Liu, J., Wang, Q., Wang, C., Yin, Z., and Wu, C. (2017). "Lactic acid production from Sophora flavescens residues pretreated with sodium hydroxide: Reutilization of the pretreated liquor during fermentation," Bioresources Technology 241, 915-921. DOI: 10.1016/j.biortech.2017.06.005

Zhang, Y. H. P., and Lynd, L. R. (2004). "Toward an aggregated understanding of enzymatic hydrolysis of cellulose: Noncomplexed cellulase systems," Biotechnology and Bioengineering 88(7), 797-824. DOI: 10.1002/bit.20282 
Zheng, Y., Zhang, S., Miao, S., Su, Z., and Wang, P. (2013). "Temperature sensitivity of cellulase adsorption on lignin and its impact on enzymatic hydrolysis of lignocellulosic biomass," Journal of Biotechnology 166(3), 135-43. DOI: 10.1016/j.jbiotec.2013.04.018

Zhu, S., Wu, Y., Yu, Z., Chen, Q., Wu, G., Yu, F., Wang, C., and Jin, S. (2006). "Microwave-assisted alkali pre-treatment of wheat straw and its enzymatic hydrolysis," Biosystems Engineering 94(3), 437-442. DOI: 10.1016/j.biosystemseng.2006.04.002

Article submitted: August 12, 2018; Peer review completed: November 5, 2018; Revised version received and accepted: December 20, 2018; Published: January 7, 2019.

DOI: 10.15376/biores.14.1.1379-1389 